\title{
Universal Design: Moving the Americans With Disabilities Act From Access to Inclusion
}

\author{
Mary A. Hums, Samuel H. Schmidt, \\ Andrew Novak, and Eli A. Wolff
}

\begin{abstract}
The Americans with Disabilities Act (ADA) has greatly improved the lives of people with disabilities in the United States. Initially thought to primarily require removal of physical barriers, the ADA has consistently been applied broadly to encompass all aspect of entities' programs, services, and operations. As entities endeavored to comply with the ADA, several useful management strategies have emerged, one of which is this concept of Universal Design (UD). Universal Design guides managers in meeting their legal obligations under the ADA and also creating a more fully inclusive environment for employees and customers. "Universal Design is a framework for the design of places, things, information, communication and policy to be usable by the widest range of people operating in the widest range of situations without special or separate design" (IHCD, 2015b). The authors explain the important relationships between ADA's legal mandate and Universal Design as a management strategy.
\end{abstract}

"Accessibility is a mandate; universal design is a movement" (Knecht, 2015, para. 1).

The civil rights movement of the 20th century produced radical changes in United States culture. New laws were enacted to protect citizens from discrimination based on race, gender, age, and disability. Since its passage 25 years ago, the Americans with Disabilities Act (ADA) has greatly improved the lives of people with disabilities in the United States (ADA National Network, 2015). The purpose of the ADA, as stated in the legislation's preface, is to provide clear and consistent federal standards and enforcement for the "elimination of discrimination against individuals with disabilities" (42 U.S.C. § 12101(b)(1)-(4)).

The ADA provides comprehensive civil rights protections to individuals with disabilities. The breadth of the legislation is represented across the three primary titles governing employment (Title I), public agencies and public transportation (Title II), and public accommodations (Title III) (42 U.S.C. § 12101, et seq.). Title III has had the most significant impact in the sport industry and will be the focus of the discussion and examples herein. Title III of the ADA prohibits discrimination

Hums (mhums@louisville.edu) and Schmidt are with the University of Louisville. Novak is with George Mason University. Wolff is with Brown University and the Institute for Human Centered Design. 
on the basis of disability with respect to goods, services, or facilities determined to be places of "public accommodation," including lodging, education and health facilities, stores, restaurants, and transportation (42 U.S.C. $\$ 12181$, et seq.). Sport and recreation facilities are specifically included in the definition of "public accommodation," including as illustrative examples "a gymnasium, health spa, bowling alley, golf course, or other place of exercise or recreation” (42 U.S.C. § 12181). According to the United States Access Board, an independent government agency that develops criteria for disability access, "[r]ecreational facilities, including sports facilities, are among the facilities required to comply with the ADA" (n.d., para. 1). The ADA has been instrumental in opening up access in sport facilities for people with disabilities, including, for instance, ticket sales at sporting events and accessible design for recreational facilities (28 C.F.R. § 36.302(f) (2011); US Department of Justice, 2010a).

At first glance, it may appear as though the ADA's impact on sport venues relates primarily to access to the physical spaces in and around a stadium or arena. However, the stadium experience for a spectator includes all aspects of the core product, the physical facility, and the service personnel (Greenwell, Fink, \& Pastore, 2002; Shreffler \& Ross, 2013). Universal Design strategies enable sport managers to systematically and creatively evaluate whether their venues, programs, and services are fully accessible consistent both with ADA legal standards and across a wide range of inclusive factors. For example, sport managers may focus on personnel attitudes toward and interactions with people with disabilities as they employ creative approaches to providing a "social experience for disabled fans that is as similar as possible to that enjoyed by other spectators and avoid any strategy that might tend to isolate or marginalize those with disabilities" (Green, 2014, para. 12).

A milestone such as the 25th anniversary of the ADA allows discussions around making life for people with disabilities even more inclusive than the dictates of the law. There is much to celebrate when acknowledging this landmark piece of civil rights legislation that was enacted a generation ago. It is also essential, however, to recognize a great deal remains to be done for people with disabilities to enjoy full inclusion in daily life in US society. As public and private entities began implementing the ADA, structural essentials such as curb cuts, elevators, and "handicap" parking spaces became required by law and the public became accustomed to seeing and utilizing them. These improvements transformed accessibility. Access, however, is just one aspect of inclusion and this article will discuss the concept of Universal Design as applied in sport settings.

\section{The Legal Framework for Inclusion}

Title III of the ADA prohibits discrimination on the basis of disability in "public accommodations," which generally includes all public or private entities that are open to the public at large, including lodging, restaurants, entertainment facilities, retailers, transit, recreation, schools, and many others (42 U.S.C. $§ 12181(7)$ ). This provision no doubt extends to the world of sport, including observing and participating in sport and accessing the full range of athletic venues such as stadiums, gymnasiums, health clubs, and others. Limited exemptions exist only for qualifying religious and truly private membership organizations. Title III applies to both 
existing and newly constructed facilities. Facilities constructed after 1993 must be "readily accessible to and usable by individuals with disabilities" unless structurally impracticable, while facilities built before that date have a duty to remove barriers "to the maximum extent feasible" (42 U.S.C. § 12183).

The statutory framework of Title III is supplemented by extensive regulations promulgated by the U.S. Department of Justice. Regulations specific to sport venues require that sports stadiums and other venues must provide "equal enjoyment" for patrons with disabilities (42 U.S.C. § 12182(a)). As McArdle (2009) explains, access to sporting venues under these regulations generally includes voluminous and relatively noncontroversial provisions, such as disability access to lavatories, automated teller machines, doorways, concessions, water fountains, or ticket counters. Some of the regulations still present compliance challenges for venue operators even though detailed compliance manuals and standards have been developed. For example, the 2010 ADA standards require at least one accessible seat per 25 seats up to 150 seats, and an additional accessible seat for every 150 seats up to 5,000, and then one additional accessible seat for every 200 seats thereafter. This matrix also applies to club boxes, luxury boxes, and suites, as well as team or player seating areas (ADA, 2010). For new construction, the regulation at 28 C.F.R. $§ 36.406$ (f) requires designated wheelchair and companion seating along an accessible route in a fixed seat assembly area, including specific criteria for stadium-style seating. Despite the detailed criteria provided in the regulations, litigation has resulted over several aspects of these regulations. The controversial "line of sight" requirement is just one example of litigation related to the scope and meaning of the regulations.

The line of sight requirements addressed seating configurations in stadiums and arenas where the seating layout and slope do not always provide equal viewing angles for persons in wheelchairs. In Paralyzed Veterans of America v. D.C. Arena L.P. (1997), the U.S. Court of Appeals for the District of Columbia Circuit found that the arena was in "substantial compliance" with the 1991 regulations even if some wheelchair areas did not have an unimpeded line of sight over standing spectators. According to the appellate court in D.C. Arena, ensuring that between $75 \%$ and $88 \%$ of designated wheelchair areas had unfettered sightlines was sufficiently compliant with the regulations. (D.C. Arena, p. 589). Later courts, however, were more willing to demand total compliance in requiring all wheelchair seating arrangements to have unimpeded views in stadium seating (see, e.g., United States v. Hoyts Cinemas Corp.). Conflicting case law as to whether total compliance or substantial compliance was sufficient and whether an unimpeded line of sight was enough even if the viewing angle was less than optimal led to a subsequent regulatory change in 2010 that clarified wheelchair access to stadiums (McArdle, 2009). The 2010 ADA standards for Accessible Stadiums require that persons in wheelchairs have a line of sight over the heads of standing spectators in the row immediately in front of them when spectators are expected to stand during a performance or event (ADA, 2010). Otherwise, persons in wheelchairs need only have a line of sight over spectators who are seated (ADA, 2010).

The example above illustrates some of the detailed and comprehensive regulations applicable to stadiums and arenas as well as the resulting jurisprudence related to stadium accessibility issues. A thorough understanding of the regulations and relevant court decisions is useful to sport venue operators to meet ADA compliance challenges related to physical access to a facility and its amenities. Of equal 
importance for sport managers and venue operators is the need to fully understand the breadth of the ADA's mandate.

As mentioned previously, in addition to physical access, Title III of the ADA created an affirmative obligation to modify policies, goods, services, or programs for persons with disabilities, including those of a sporting or athletic nature (42 U.S.C. $§ 12182(b)(2)$ ). A venue must modify policies, procedures, and programs if such requested modifications are reasonable and necessary, and do not "fundamentally alter the nature" of a service or program or result in an "undue burden" (42 U.S.C. $§ 12182(b)(2)(i i)-(i i i)$. Given the breadth of the ADA's mandate and willingness of patrons to pursue litigation to enforce their rights, it is imperative for sport managers to be proactive and creative in their compliance efforts. Evaluating ADA obligations in a manner consistent with principles of Universal Design could improve the lives of persons with disabilities and create opportunities for business innovation. Universal Design provides a useful framework for sport managers to follow and is illustrated in detail in the following section.

\section{Universal Design as an ADA Management Strategy}

The first real mention of what was then called barrier-free design, can be found in the 1950s (Welch \& Palames, 1995). "In Europe, Japan, and the United States, barrier-free design developed to remove obstacles in the built environment for people with physical disabilities. It followed the companion social policy of moving people with disabilities from institutional settings to the community" (Institute for Human Centered Design, 2015a, para. 2). While these early efforts were laudable, people with disabilities still tended to be segregated, and not until the 1970s did the notion of normalizing and integrating people with disabilities into greater society begin to take shape. In the United States, building on the foundations laid by the civil rights movement in the 1960s and the Civil Rights Act of 1964, the disability rights movement gained momentum (Center for Universal Design, 2008). That momentum allowed for expanded thinking about access and soon the idea of design became incorporated into the discussion. "For the first time, design was recognized as a condition for achieving civil rights" (Institute for Human Centered Design, 2015a, para. 2). The Rehabilitation Act of 1973 (Section 504) prohibited disability discrimination in federal government services and programs which included schools, universities, and other recipients of federal financial assistance. Section 504 emphasized the concept of equal access for persons with disabilities (29 USCS § 794). The ADA reinforced this approach and extended the mandate of integrating people with disabilities fully and equally into all aspects of society and culture including employment, public entities, and access to public accommodations. The Department of Justice issued regulatory guidance in the 1991 and 2010 ADA Standards for Accessible Design. Accessible Design describes "a site, building, facility or thereof that complies with the minimum accessibility standards as set forth under the Americans with Disabilities Act, Architectural Barriers Act or local building code" (28 C.F.R. Part 36, Appendix D, § 3.5; Skulski, 2007, para. 5). In this article, the term "Accessible Design" will be used to describe design aspects that are in minimal compliance with Standards of Accessible Design and 
other federal laws. Numerous resources were created to aid sport managers in meeting the architectural access and design requirements of the ADA (United States Access Board, 2004; U.S. Department of Justice, 2010a). Beyond the physical access and design elements, however, guidance is still needed and developing. Universal Design management strategies contribute a useful framework for sport and recreation managers.

\section{University Design Concepts and Principles}

The concept of Universal Design is attributed to two wheelchair users and polio survivors, Ron Mace and Selwyn Goldsmith. Mace and Goldsmith had a keen interest in architecture and design. They "both had the credibility of being wheelchair users bent on summoning attention to a bigger idea. They saw mandated accessibility as "a valuable floor but too narrowly focused on people with disabilities to align with the need and opportunity to design for an increasingly diverse world" (Fletcher, in press, p. 10). The definition of Universal Design sprang from their vision. According to Fletcher (in press),

Ron Mace, FAIA was a key figure in the development in the U.S. of the Principles of Universal Design in 1997. Ten authors (Bettye Rose Connell, Mike Jones, Ron Mace, Jim Mueller, Abir Mullick, Elaine Ostroff, Jon Sanford, Ed Steinfeld, Molly Story, and Gregg Vanderheiden) from five U.S. organizations compiled the Principles that were then copyrighted to the North Carolina State University, the Center for Universal Design. The definition of Universal Design introduces the principles: "The design of products and environments to be usable by all people, to the greatest expect possible, without the need for adaptation or specialized design." (p. 10)

Over time, the reach of the legal requirements for more accessible design blossomed until today we have arrived at a more detailed definition of Universal Design. According to the Institute for Human Centered Design (2015b, para. 1), "Universal Design is a framework for the design of places, things, information, communication and policy to be usable by the widest range of people operating in the widest range of situations without special or separate design. Most simply, Universal Design is human-centered design of everything with everyone in mind."

Universal Design encompasses five distinct environments including physical aspects of a facility or a space (built environment, information environment, and communication environment) as well as intangible aspects (policy environment and attitudinal environment):

1. Built environment

2. Information environment

3. Communication environment

4. Policy environment

5. Attitudinal environment (Institute for Human Centered Design, 2011).

For purposes of illustrating these five environments, think of a sport arena. The built environment includes the physical indoor and outdoor aspects of an 
arena. This would include the typical accessibility modifications such as curb cuts, accessible washrooms, wide aisles and entranceways, and parking areas. The information environment encompasses how information is passed along to patrons at a facility. Typical arena signage includes location of seating sections, concessions, elevators, washrooms, and exits. These need to be large enough, sufficiently well lit, and placed in easy to spot locations. The communication environment describes how an arena passes information to potential visitors. Phones would include options for persons with auditory disabilities, websites would have large fonts and audio features, and provide easy access to links about services for patrons with disabilities.

As stated previously, these three environments related to physical elements of a facility are directly correlated with ADA requirements. The ADA, however, is not limited to physical access and tangible environment as will be seen in these next two environments. The policy environment presents evidence of policies that impact equality of experience for all arena visitors. Policies for service animals, reseating of patrons with disabilities who inadvertently purchased inaccessible seats, or even smoking policies fit in this category. The ADA sets the legal groundwork for these policies, and sport managers may choose to incorporate Universal Design to meet legal requirements. Finally, there is the attitudinal environment, which relates to staff or administrative behavior or beliefs. Arena managers need to train employees how to appropriately interact with patrons with disabilities, for example, by using a "Just ask, just listen" approach to helping their game day experience be as positive as possible (Toronto 2015 Pan Am / Parapan Am Games, 2015).

\section{Implementation and Usage of Universal Design Principles}

In addition to the five environments, Universal Design also includes seven principles for implementation (Universal Design, 2015, para. 2):

1. Equitable Use: The design is useful and marketable to people with diverse abilities

2. Flexibility in Use: The design accommodates a wide range of individual preferences and abilities

3. Simple and Intuitive Use: Use of the design is easy to understand, regardless of the user's experience, knowledge, language skills, or current concentration level

4. Perceptible Information: The design communicates necessary information effectively to the user, regardless of ambient conditions or the user's sensory abilities

5. Tolerance for Error: The design minimizes hazards and the adverse consequences of accidental or unintended actions

6. Low Physical Effort: The design can be used efficiently and comfortably with minimum fatigue

7. Size and Space for Approach and Use: Appropriate size and space is provided for approach, reach, manipulation, and use regardless of user's body size, posture, or mobility. 
Sport managers who successfully include Universal Design in a facility's design process, operation, and evaluation may more easily and effectively manage their ADA compliance while promoting diversity and inclusion. A key component of the Universal Design process is the utilization of people known as user experts. According to Ostroff (1997),

A user/expert can be anyone who has developed natural experience in dealing with the challenges of our built environment. User/experts include parents managing with toddlers, older people with changing vision or stamina, people of short stature, limited grasp or who use wheelchairs. These diverse people have developed strategies for coping with the barriers and hazards they encounter everyday. The experience of the user/expert is usually in strong contrast to the life experience of most designers and is invaluable in evaluating both existing products and places as well as new designs in development. (para. 1)

It is essential to involve user experts from the beginning of the facility design process through the daily implementation of facility operation. These user experts are as critical to the building process as the architects, planners, programmers, and construction firms.

When implemented correctly, the principles of Universal Design go beautifully unnoticed (Live Smart Design, 2015). Everyday items, for example, featuring the principles of Universal Design seldom draw attention. Single lever faucets, motion sensor lights, electric toothbrushes, closed captioning, Velcro, and automatic doors are all examples of Universal Design in everyday life. Implementing and using Universal Design is simple and provides opportunities for use by any individual, regardless of ability, culture, gender, age, language differential, or any other characteristic.

\section{Universal Design Examples in Sport Settings}

Sport can be consumed either as a participant or a spectator. Universal Design can be seen in both of these settings, such as in playgrounds or bowling alleys and also public assembly facilities. The following sections will discuss Universal Design in a variety of sport settings.

\section{Universal Design in Sport and Recreation Programs}

Principles of Universal Design can inform modifications to sports programming to make activities fully accessible to persons with disabilities. Under Title III of the ADA, an owner of a public accommodation must make reasonable modifications of eligibility rules, competition rules, or other policies and procedures for persons with disabilities so long as they are reasonable and necessary and do not fundamentally alter the nature of the program (42 U.S.C. $\S 12182(\mathrm{~b})(2)(\mathrm{A})(\mathrm{ii})$ ); PGA Tour, Inc. v. Martin (2001)). The following examples illustrate Universal Design in action in a recreational setting.

In 2007, the National Center on Accessibility at Indiana University at Bloomington created a resource for applying the principles of Universal Design to playgrounds for not only children, but their accompanying adults as well. The resource 
outlines the seven principles listed above as they would appear at a Universally Designed playground (Skulski, 2007). Equitable Use describes the playground's ability to accommodate every person wishing to interact with it. No individual should be segregated due to his/her need to use an assistive device. By using Universal Design practices that encourage Flexibility in Use, sandboxes and sandtables of various heights can be installed in the playground to promote inclusion. An example of Simple and Intuitive Use at a playground is Freenotes, which are sound sculptures designed to be played by people regardless of age, gender, ethnicity, mobility, visual, auditory or mental abilities and popular due to their ease of use (Accessible Playgrounds, n.d.). Perceptible Information refers to how information is passed to someone using a product or service. Instead of having a single board with information written in one language, designers could color code the equipment for age appropriateness. Keeping playground safety in mind, Tolerance for Error limits the possibility of mistakes that may result in injury. Another principle to ensure safety is the principle of Low Physical Effort whereby it is not too difficult or tiring for any one person to access the playground. Finally, Size and Space for Approach and Use ensures that the playground is approachable and useable for individuals of all body shapes, sizes, and abilities. Skulski believes this final principle captures the spirit of Universal Design where “... play components are designed for Poppa Bear, Mamma Bear and Baby Bear” (Skulski, 2007, para. 30).

The sport of bowling also provides examples of Universal Design principles in action. In 1988, a fad swept across bowling alleys in the United States: adding bumpers to lanes to prevent the ball from going in the gutter. Such bumpers may not strictly be required under the ADA as such modifications fundamentally "alter" the nature of bowling, but from a Universal Design perspective, their use is inclusive for persons with disabilities and economically profitable for bowling alleys. Zena Sheinberg, a special education teacher, conjured up the idea after watching multiple mentally impaired students struggle with the frustrations of bowling (Libman, 1988). The design, created to help those students, turned into a Universal Design product where individuals of different physical or mental abilities and ages can bowl without the fear of failing. Given the success of bumpers, bowling alley operators have developed more equipment to improve the bowling experience-ball ramps and ball pushers (United Cerebral Palsy, 2015). All these equipment modifications were designed to provide for greater social inclusion and enhance the experience of those participating in the sport.

Brunswick Bowling, a major supplier of bowling alley equipment, manufactures and sells a bumper system called Pinball Wizard and recognizes the importance of Universal Design. According to Brunswick, "Pinball Wizard's universal design allows for installation with any lane type and interfaces with the most modern scoring and pinsetter systems. Finally, whole families can bowl on the same lane with the right degree of challenge and more fun for everyone!" (Brunswick, 2015, para. 10).

Universal Design can be seen in sport programming in higher levels of competition as well. In 1975, the Boston Marathon experienced something never seen before when Bob Hall completed the race in a wheelchair. The race director informed Hall, who was not recorded as an official entrant for the race, he would qualify to earn the race medal if he completed the Marathon in under three hours. Two hours and 58 minutes after the start of the race, Hall crossed the finish line, inspiring the Boston Athletic Association to recognize and certify wheelchair athletes as 
official entrants (Vega, 2015). The inclusion of wheelchair athletes into this major international event was just one step in providing greater inclusion for all athletes. The 2016 Boston Marathon qualifying times (separated by age) included a Push Rim Wheelchair Division, a Blind/Visually Impaired Division, Mobility Impaired Program, a Hand Cycle Program, and a Duo Team program, comprised of one able bodied person pushing a permanently disabled person in a racing wheelchair (Boston Athletic Association, 2015).

Another sport organization recently taking strides toward greater inclusivity at the programmatic level is the largest conference in the National Collegiate Athletic Association (NCAA), the Eastern Collegiate Athletic Conference (ECAC). In early 2015, the ECAC announced the addition of wheelchair basketball, sledge hockey, goalball, and sitting volleyball as varsity sports (ECAC, 2015). The ECAC is providing student-athletes with disabilities the opportunities to compete at the intercollegiate level and vie for ECAC championships. The conference added these four sports to provide greater inclusion for athletes with disabilities. The ECAC is on the trajectory to ultimately bring Universal Design to intercollegiate athletics.

\section{Universal Design in Venues}

As noted above, Title III of the ADA has spawned considerable litigation over seating arrangements in sport and entertainment venues, particularly concerning "line of sight" and vantage points for wheelchair users (McArdle, 2009). As a result of this litigation, an updated regulation at 28 C.F.R. $§ 36.308$ provides guidelines for wheelchair and companion seating in assembly areas. The Department of Justice's 2010 ADA Standards provide further guidance for wheelchair access in large assembly areas, including standards specific to sports venues. These standards provide, for instance, such provisions as ramp access for team and player seating (Standard 206.7.9), accessibility to both sides of a court (Standard 206.2.12), wheelchair access in dining venues (Standard 206.2.5, Exception 3), and locker access (Standard 225.2.1).

Despite this detail, Universal Design principles could nonetheless supplement the ADA mandate in a way that further promotes inclusion of persons with disabilities without being overly burdensome. Green Point stadium in Cape Town, South Africa provides a nice example of Universal Design in new stadium construction, as it was built for the World Cup in 2010. One central element in the design of signage is use circles and colors. "All information such as numbers, direction signs, colours and pictograms is applied to circular surfaces which can be freely combined. . . . Simple geometrical forms like a circle are particularly suitable for a barrier free communication of information. The use of colours means the information is easy to understand for people who cannot read, which in South Africa is by no means an aspect which can be neglected" (Kling, Krueger, Baur et al., 2013, p. 43).

The ADA has struggled to evolve with new technological advances. Here, too, Universal Design principles could prove useful. Litigation over closed captioning of announcements, songs, promotional advertisements, referee calls, and halftime presentations are illustrative (Charmatz, Hedges-Wright \& Ward, 2011). Title III of the ADA provides only that private entities "furnish appropriate auxiliary aids and services where necessary to ensure effective communication with individuals with disabilities," which could include closed captioning (28 C.F.R. § 36.303(c)). 
However, as with modifications to the play or practice of sport itself, a private entity is not required to provide an auxiliary service or aid to spectators if doing so would "fundamentally alter the nature of goods, services, facilities, privileges, advantages, or accommodations being offered or would result in an undue burden, i.e., significant difficulty or expense" (28 C.F.R. § 36.303(a); Haney, 2011).

Individuals who are deaf or hard of hearing have used the ADA to require closed captioning of television screens in sports stadia and other live entertainment venues. In Feldman v. Pro Football, Inc., (2008), the U.S. District Court for the Southern District of Maryland sided with a group of hearing-impaired NFL fans who requested closed captioning on the public address system announcements on the Sony JumboTrons located at each end of FedEx Field in Landover, Maryland. The Feldman decision has been criticized as limited in its practical application, as it only required that the Washington team and FedEx Field provide captioning, not all National Football League (NFL) teams (Haney, 2011). In addition, while the ADA's accessibility requirements are binding on all new construction, existing facilities are subject to the balancing test described above in which the costs to the facility owners must be considered. In this instance, the standard is whether removing architectural and communication barriers is "readily achievable," defined as "able to be carried out without much difficulty or expense" (42 U.S.C. $§ 12181(9)$; 42 U.S.C. $\S 12182$ (b)(2)(iv)). As Lower and Petersen (2010) write, however, the number "of LED screen installations in sport venues increased enormously throughout the 1990s and the first decade of the 2000s, and this growth is likely to continue especially in the collegiate and high school levels." The closed captioning boards, however, are often situated in a select few locations, and at times are too far away for some individuals to see. In the realm of closed captioning, principles of Universal Design would create a more accessible space for persons with disabilities beyond technical compliance with the minimal ADA standard.

The use of smartphones has created a way to showcase Universal Design principles and provide more social inclusion. The University of Phoenix Stadium offers closed captioning on an individual's smart phone for Arizona Cardinal NFL games, The Fiesta Bowl, The Super Bowl, college football games, and soccer matches (University of Phoenix Stadium, n.d.). Instead of focusing on one end of the stadium to read announcements and referee calls, individuals can look to their personal phone for captions. Improvements in technology, similar to the closed captioning on personal phones, will continue to expand implementation of Universal Design.

When examining sport venues, the discussion can be broadened to include recreational sport venues as well. Another clear example of Universal Design in a sport venue is Miracle League baseball. In 1999, children with disabilities were invited to play in the Rockdale Youth Baseball Association (Miracle League, 2015). The players wanted to wear team uniforms, make plays in the field, and round the bases just like the able-bodied participants, however concerns over a safe playing surface were raised. Within one year, the Miracle League Field was completed. The complex included "... a cushioned rubberized surface to help prevent injuries, wheelchair accessible dugouts, and a completely flat surface to eliminate any barriers to wheelchair-bound or visually impaired players" (Miracle League, 2015, para. 6). Accessible restrooms, concession stands, and a picnic pavilion provided for greater inclusion. Today, more than 275 Miracle League organizations operate across the United States, Puerto Rico, Canada, and Australia, serving over 200,000 
children and young adults. The inclusion of "Buddies" (able-bodied children who play baseball, youth church groups, local organizations and Boy Scouts and Girl Scouts) brings together a community of differing abilities, cultures, and ages.

Miracle League sites have indicated that Universal Design was part of the initial plan. At the Alpharetta Adapted Sport Complex, home to the North Metro Miracle League,

Attention to detail, accessibility and universal design has created a proto-type for future adapted sports facilities across the country. Any design element that unnecessarily differentiates between people with and without disabilities has been eliminated. Universal design plays a major role in the structures we build, the material we write and the programs we design. (NCHPAD, 2015, para. 2)

When Universal Design was first introduced, the purpose was for designs to be useable by all persons regardless of special need. Since then, Universal Design has evolved into allowing for social inclusion. Sport managers who implement Universal Design principles into their facilities, equipment, and coaching styles will enjoy a competitive advantage over those who fail to do so.

\section{Universal Design and Sport Equipment and Products}

Sport equipment is constantly being upgraded and redesigned. Prosthetics have become lighter, companies are producing less expensive sport wheelchairs, and there has never been as much adaptive sports equipment available as there is today (Disabled Sports USA, n.d.; Dyson 2012; Hambrick, Hums, Bower, \& Wolff, 2015; Wheelpower, 2015; Wrenn, 2012). Sir Philip Craven, President of the International Paralympic Committee has publically acknowledged "advancements in technology in terms of equipment are also benefitting athletes at all levels, from the grassroots right through to the Paralympic Games" (International Paralympic Committee, 2014, para. 18). Under the framework of Title III of the ADA, as noted above, sports facilities and events may be required to allow or provide modified sporting equipment for persons with disabilities, so long as the equipment is reasonable and necessary and does not alter the fundamental nature of the program (42 U.S.C.S. § 12182(b)(2)(A)(ii)). Manufacturers are beginning to recognize that a new design can promote inclusion through Universal Design and increase profitability. The examples provided next, which include fitness equipment and a new Nike shoe design, benefit people with disabilities but also make sport participation more accessible to anyone.

Some examples of Universal Design principles are present in the American Society of Testing and Materials (ASTM) criteria that were developed to assist facility managers with making their facilities more Universal Design friendly. According to Hurley and Axelson (2012, para, 1), "The Department of Justice (DOJ) is now mandating (effective March 2012) that accessible fitness equipment must be provided to meet the needs of people with disabilities in public fitness facilities." In accord with this, the ASTM drafted the ASTM UDFE [Universal Design for Fitness Equipment] Standard which "gives manufacturers, health club managers, fitness trainers, and people with and without impairments the tools they need to choose fitness equipment that will meet their needs. Fitness facilities can also expect to benefit from an increase in membership" (Hurley \& Axelson, 2012, Discussion 
section). The ASTM created these criteria because it recognized the importance of physical activity for every individual and promoted the ASTM's desire to provide those benefits to the widest possible range of individuals.

Recently, Nike announced the release of a new shoe, the FLYEASE, which illustrates Universal Design in sport equipment (Fast Company, 2015). The idea for the design had its genesis from a teen-ager with cerebral palsy who contacted Nike. The young man related how he was perfectly capable of dressing himself, but needed assistance because he could not tie his own shoes due to his disability. Intrigued by the request, Nike designers created

A design that is so simple that the solution seems obvious. The boots have a zipper that runs around the back of the ankle, and the oversized zipper-pull lets the wearer close it with one hand. The zipper-pull then attaches around the front of the ankle, a flat strip across the face of the shoe. This combination of one-handed zipper and the low-opening heel mean the shoes can slip on and off easily and are simple to secure. The idea is so neat that you probably want a pair even if you have no trouble with regular shoelaces. (Fast Company, 2015, paras. 4-5)

This shoe is an outstanding example of how a little creativity promotes inclusion. People with disabilities can now "lace up" their Nikes just like anyone else.

\section{Universal Design and Advertising}

Principles of Universal Design can also assist sport marketers in identifying and creating advertising and promotions highlighting inclusion and diversity. For example, the Guinness beer company recently ran an advertising video featuring wheelchair basketball players. Near the end of the video as the pick-up game at the gym winds down, the players head to the locker room. But what made the video so striking was that of all the players, merely one was actually a permanent wheelchair user. The others were men who just wanted to play basketball and include their friend (Ad Week, 2014). This example illustrated the concept of inclusion and how Universal Design can actually transform our perception of sport. What we see here is how the sport itself is redesigned to be accessible to all by having able-bodied players use a piece of sporting equipment, a basketball chair, to enable them to play the sport of wheelchair basketball.

The previously mentioned Nike FLYEASE shoe is now available on the Nike. com website. It also debuted on the feet of US basketball athletes at the Special Olympics World Games in Summer of 2015 (Diaz, 2015). LeBron James has also lent his support to the new shoe, potentially giving it wider marketability.

\section{Universal Design-What Will Sport Look Like When the ADA Celebrates Its 50th Anniversary?}

"Embracing tenets of Universal Design should not be about US and THEM, but rather WE. The elderly, parents pushing baby strollers, businessmen with roller bags in the airport, a family member who may be hard of hearing, and young children with learning differences, to name only a few, will all benefit" (Blauwet, 2015, p. 2). 
After 25 years, the ADA has provided individuals with disabilities greater access to sport. The question remains, what will sport look like when the ADA celebrates its 50th anniversary (Wolff \& Hums, 2014)? The question is impossible to answer today, but an optimistic eye would look toward Universal Design to provide part of that answer. Through Universal Design, sport managers may embrace creativity and inclusion to provide more opportunities for every individual, including individuals with disabilities. Universal Design transcends the original concept of Accessible Design and encourages sport managers to think beyond the minimum requirements that allow individuals with disabilities to access sport and instead encourage creative and proactive inclusion of individuals with disabilities in all aspects of sport.

One area of increasing opportunity and concern in coming years will be the extent to which "public accommodation" comes to include the internet and smartphone applications. Currently, federal courts are divided as to whether private websites constitute places of public accommodation under Title III of the ADA. The United States District Court for the Northern District of California held that a website is only a place of accommodation when there is a "nexus" between a service offered over the internet and a physical place of public accommodation, such as purchasing online from a brick-and-mortar retailer (Nat'l Federation of the Blind v. Target Corp., (2006)). By contrast, in a suit involving Netflix, which does not have a physical presence, a Massachusetts federal district court determined that streaming services over the internet are a place of public accommodation under Title III even without a "nexus" to a physical place (Nat'l Ass'n of the Deaf v. Netflix, (2012)). Such cases have important implications for sport as well, including for watching sporting events, using sport-related social media, and even for sports betting. Principles of Universal Design can be used to manage virtual as well as real world physical environments.

The application of Universal Design principles and the involvement of userexperts by sports managers will continue to evolve and expand the inclusion and integration of people with disabilities into all aspects and areas of sport. For the 50th anniversary of the ADA, we can envision a sporting environment and sports culture that is truly inclusive, upholding and embracing the principles of Universal Design in all areas of the built, communication, information, policy, and attitudinal environments. In addition, any discrimination against people with disabilities can be quickly recognized and addressed by all stakeholders involved. Sport managers embracing the concept of Universal Design will be seen as leaders in promoting inclusion, acceptance, and valuing of people with disabilities in the next 25 years and beyond.

\section{Acknowledgments}

The authors would like to gratefully acknowledge the assistance of Anita M. Moorman, J.D., in the technical preparation of this manuscript.

\section{References}

Accessible Playgrounds. (n.d.). Freenotes Harmony Park. Retrieved from http://www.accessibleplayground.net/vendors/freenotes-harmony-park/ 
Ad Week. (2014, October 3). Guinness wheelchair basketball ad spun circles around competitors in Q3. Retrieved from http://www.adweek.com/news/advertising-branding/ guinness-wheelchair-basketball-ad-spun-circles-around-competitors-q3-152865

ADA National Network. (n.d.). An overview of the Americans with Disabilities Act. Retrieved from http://adata.org/factsheet/ADA-overview

ADA National Network. (2015). ADA: Findings, purpose, history. Retrieved from http:// www.adaanniversary.org/findings_purpose

Americans with Disabilities Act of 1990, 42 U.S.C. \$12181, et seq., 2015. Arizona ex rel. Goddard v. Harkins Amusement Enterprises, 603 F.3d 666 (9th Cir. 2010).

Blauwet, C. (2015, July 22). Boston ADA $25^{\text {th }}$ anniversary celebration address. Boston, MA.

Boston Athletic Association. (2016). Participant information: Athletes with disabilities. Retrieved from http://www.baa.org/races/boston-marathon/participant-information/ qualifying/athletes-with-disabilities.aspx

Brunswick. (2015). Lane accessories. Retrieved from http://www.brunswickbowling.com/ products/lanes/lane-accessories/

Center for Universal Design. (2008). About UD: Universal Design history. Retrieved from http://www.ncsu.edu/ncsu/design/cud/about_ud/udhistory.htm

Charmatz, M., Hedges-Wright, L.L., \& Ward, M.A. (2011). Personal foul: Lack of captioning in football stadiums. Valparaiso University Law Review. Valparaiso University. School of Law, 45(3), 967-1031.

Diaz, A.C. (2015). A remarkable athlete inspires Nike's latest shoe innovation. Retrieved from http://creativity-online.com/work/nike-the-nike-flyease-story/42732

Disabled Sports, U.S.A. (n.d.). Adaptive sports equipment. Retrieved from http://www. disabledsportsusa.org/resources/adaptive-sports-equipment/

Dyson, J. (2012, September 2). Paralympics 2012: Paralympics giving athletes an edge. The Telegraph. Retrieved from http://www.telegraph.co.uk/sport/olympics/paralympicsport/9514155/Paralympics-2012-technology-giving-athletes-the-edge.html

ECAC board of directors case historic vote to add varsity sports opportunities for studentathletes with disabilities in ECAC leagues and championships. (2015, January 15). Retrieved from http://ecacsports.com/news/2014-15/sports_opportunities_for_studentathletes_with_disabilities_in_ECAC_leagues_and_championships

Fast Company. (2015). These new Nike shoes make it easy for disabled kids to lace up and play. Retrieved from http://www.fastcoexist.com/3048967/these-new-nike-shoes-makeit-easy-for-disabled-kids-to-lace-up-and-play

Feldman v. Pro Football, Inc., 579 F.Supp.2d 697 (D.Md. 2008)

Fletcher, V. (In press). Inclusive/Universal Design - People at the center of the design process. In M. Kanaani \& D. Kopec (Eds.), The Routledge handbook of architecture and design: Current and emerging trends. London: Routledge.

Green, L. (2014). Disabled spectator access to facilities: Contemporary legal standards. Retrieved from https://www.nfhs.org/articles/disabled-spectator-access-to-facilitiescontemporary-legal-standards/

Greenwell, T.C., Fink, J.S., \& Pastore, D.L. (2002). Assessing the influence of the physical sports facility on customer satisfaction within the context of the service experience. Sport Management Review, 5, 129-148. doi:10.1016/S1441-3523(02)70064-8

Hambrick, M.E., Hums, M.A., Bower, G.G., \& Wolf, E.A. (2015). Examining elite parasport athletes with sport involvement and sports equipment. Adapted Physical Activity Quarterly, 32, 1-18. doi:10.1123/apaq.2013-0070

Haney, D. (2011). Title II and Title III and the expansion of captioning for the deaf: From televisions and movie theaters to stadiums and arenas. University of Arkansas at Little Rock Law Review, 33, 465-491.

Hurley, S.L., \& Axelson, P.W. (2012). Universal Design of fitness equipment criteria to meet the new Department of Justice accessibility requirements. Proceedings of the RESNA 2009 Annual Conf. Arlington, VA: RESNA. Retrieved from http://www.resna. 
org/sites/default/files/legacy/conference/proceedings/2012/Publi cPolicy/UNIVERSALDESIGNOFFITNESSEQUIPMENTCRITERIATOMEETT HENEWDEPARTMENTOFJUSTICEACCESSIBILITYREQUIREMENTS.html.

Institute for Human Centered Design. (2011). Museum of science: The user expert perspective; Universal Design consultation. Boston, MA: Author.

Institute for Human Centered Design. (2015a). History of Universal Design. Retrieved from http://www.humancentereddesign.org/universal-design/history-universal-design

Institute for Human Centered Design. (2015b). Universal Design. Retrieved from http:// www.humancentereddesign.org/universal-design

International Paralympic Committee. (2014). IPC president praises technology in encouraging para-sport growth. Retrieved from http://www.paralympic.org/news/ipc-presidentpraises-technology-encouraging-para-sport-growth

Kling, B., Krueger, T., Baur, R., Hellstern, C., Leitte, S., Aichele-Platen, A., \& Gray, A. (2013). Signage: Spatial orientation. Munchen, GDR: Edition Detail. doi:10.11129/ detail.9783955531454

Knecht, B. (2015). Accessibility regulations and a Universal Design philosophy inspire the design process Architectural Record. Retrieved from http://archrecord.construction. com/resources/conteduc/archives/0401edit-1.asp

Libman, J. (1988, September 11). Keeping kids out of the gutter: Bumper bowling gives youngsters respectable scores. New York Times. Retrieved from http:// articles.latimes. com/1988-09-11/news/vw-2566_1_bumper-bowling

Live Smart Design. (2015). Universal Design. Retrieved from http://www.livesmartdesign. com/universal-design/

Lower, L.M., \& Petersen, J.C. (2010). Stadium accommodations and JumboTrons. Journal of Physical Education, Recreation \& Dance, 81(6), 47-52. doi:10.1080/07303084.2 010.10598492

McArdle, D. (2009). Using the Americans with Disabilities Act to inform "Access to sporting venues" under the Disabilities Convention. Boston University International Law Journal, 27, 317-344.

Miracle League. (2015). History of the Miracle League. Retrieved from http://www.themiracleleague.net/history/

Nat'l Ass'n of the Deaf v. Netflix, 869 F.Supp.2d 196 (D. Mass. 2012)

Nat'l Federation of the Blind v. Target Corp., 452 F.Supp.2d 946 (N.D. Cal. 2006)

NCHPAD. (2015). Alpharetta Adapted Sports Complex - North Metro Miracle League. Retrieved from http://www.nchpad.org/Directories/Programs/10230/Alpharetta Ada pted $\sim$ Sports $\sim$ Complex - North Metro Miracle League

Ostroff, (1997). User experts. Retrieved from http://www.humancentereddesign.org/ universal-design/userexperts

Paralyzed Veterans of America v. D.C. Arena L.P., 117 F.3d 579 (D.C. Cir. 1997)

PGA Tour, Inc. v. Martin, 532 U.S. 661, 690 (2001)

Rehabilitation Act of 1973, 29 U.S.C. \$794, et seq., 2015.

Shreffler, M.B., \& Ross, S.D. (2013). The Word-of-Mouth phenomenon: It presence and impact in a sport setting. International Journal of Sport Communication, 6, 1-18.

Skulski, J.K. (2007, October 1). Designing for inclusive play: Applying the principles of Universal Design to the playground. Retrieved from http://www.ncaonline.org/resources/ articles/playground-universaldesign.shtml

Special Olympics. (2003). Special Olympics Unified Sports handbook. Washington, DC; Author.

Special Olympics. (2015). Unified Sports. Retrieved from http://www.specialolympics.org/ unified-sports.aspx

Toronto 2015. (2015). Para-Play Demonstration Zone training. Toronto, ON: Author.

United Cerebral Palsy. (2015). Bowling for children with disabilities. Retrieved from http:// www.mychildwithoutlimits.org/act/family-life/physical-activities-for-children-withdisabilities/bowling-for-children-with-disabilities/. 
United States Access Board. (n.d.). Guide on sports facilities. Retrieved from http://www. access-board.gov/guidelines-and-standards/recreation-facilities/guides/sports-facilities

United States Access Board. (2004). Americans with Disabilities Act and Architectural Barriers Act accessibility guidelines. Retrieved from http://www.wbdg.org/ccb/ASTAND/ ada_aba.pdf

United States v. Hoyts Cinemas Corp; Civil Action Nos. 00 CV 12567 WGY

Universal Design. (2015). The seven principles of Universal Design. Retrieved from http:// www.universaldesign.com/universal-design/1761-the-seven-principles-of-universaldesign.html

University of Phoenix Stadium. (n.d.). Open captioning. Retrieved from http://www.universityofphoenixstadium.com/guest/ captioning

US Department of Justice. (2010a). 2010 ADA standards for accessible design. Retrieved from http://www.ada.gov/regs2010/2010ADAStandards/2010ADAstandards.htm\#

Vega, M. (2015, April 16). Big changes for Boston Marathon's wheelchair division. Retrieved from https://www.bostonglobe.com/sports/2015/04/16/big-changes-have-arrivedwheelchair-divisions/ilwQ6lzj988ZSHwVNzdzpO/story.html

Welch, P., \& Palames, C. (1995). Strategies for teaching Universal Design. Boston: Adaptive Environments Centers and MIGS Communication.

Wheelpower. (2015). Motivation launch affordable sports wheelchair. Retrieved from http:// www.wheelpower.org.uk/WPower/index.cfm/news/motivation-launch-affordablesports-wheelchair/

Wolff, E.A., \& Hums, M.A. (2014, December 1). The future of sport. Huffington Post. Retrieved from http://www.huffingtonpost.com/eli-wolff/the-future-of-sport_b_6244634.html

Wrenn, E. (2012, September 4). From the wheelchair based on an F1 car to the "Terminator" exo-skeleton suit: How technology is transforming the Paralympics. Daily Mail. Retrieved from http://www.dailymail.co.uk/sciencetech/article-2198013/Paralympics2012-How-technology-transforming-Games.html 